Archive for

Organic Chemistry

Arkivoc 2020, part iv, 79-85

\title{
Ligand exchange of aryl iodine dicarboxylates to form reagents with differing solubilities
}

Vanie Seecharan, Lyse Armand, Jennifer Noorollah, Nirvanie Singh, Andrew Zhang, Kevin P. Freddo, Nicholas Spatola, Sailesh Prasad, Azka Chaudhry, Su Wint War, I. F. Dempsey Hyatt, ${ }^{*}$ and Daniel L. Silverio*

Department of Chemistry, Adelphi University, One South Avenue, Garden City, NY, 11530, United States of America

Email: dsilverio@adelphi.edu

Received 12-19-2020

Accepted 03-27-2021

Published on line $04-07-2021$

\section{Abstract}

Hypervalent iodine (HVI) reagents are employed in organic synthesis as versatile, proficient, and environmentally friendly reagents. Despite the utility of such reagents, the application of HVI reagents, especially phenyliodonium diacetate (PIDA), has been limited due to its poor solubility in a myriad of solvents. The aggregated and polymeric structures of many HVI reagents account for their poor solubility, thus limiting the reactivity and use of HVI reagents in reactions in non-polar solvents. The research presented herein outlines ligand exchange reactions of universal carboxylic acids promoted by phenyliodonium diacetate (PIDA) reagents, in which the acetate moiety of PIDA is modified, ultimately enhancing the solubility and reactivity of HVI reagents.

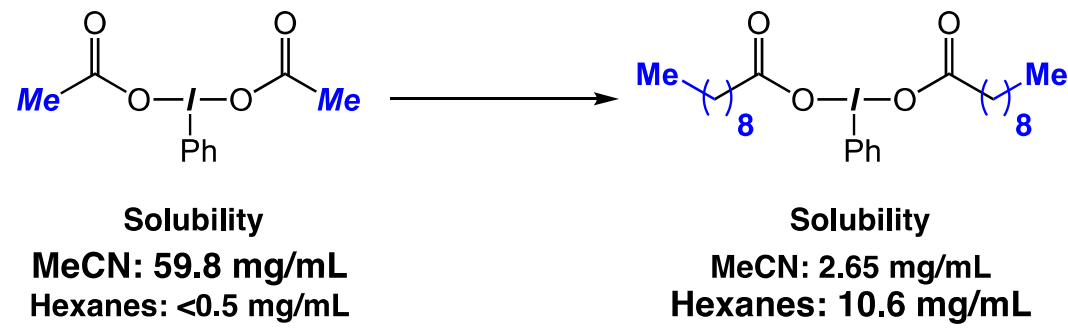

Keywords: Hypervalent iodine, solubility, PIDA, ligand-exchange 


\section{Introduction}

The reactivity of hypervalent iodine (HVI) compounds has emerged as a major area of study in the synthetic community. ${ }^{1,2}$ The reactivity of $\mathrm{HVI}$ compounds are comparable to the chemistry of transition metals in that $\mathrm{HVI}$ reactions have congruent mechanisms involving oxidative addition, ligand exchange, and/or reductive elimination. ${ }^{3}$ The chemistry of hypervalent iodine(III) reagents (also known as $\lambda^{3}$-iodanes) are well-known for their ability to facilitate oxidative transformations, ${ }^{4,5}$ photoredox reactions, ${ }^{6,7} \mathrm{C}-\mathrm{C}$ bond formations, ${ }^{8-10} \mathrm{C}-\mathrm{H}$ activations, ${ }^{11-13}$ and a plethora of other synthetically useful reactions have been covered in reviews. ${ }^{1,14-19}$

The diversity of HVI reactions is unarguable yet can be limited by the physical properties of the most commonly used commercially available HVI reagent, phenyliodonium diacetate (PIDA). PIDA is used in organic synthesis for oxidative transformations yet poor solubility of the compound in nonpolar solvents can result in sluggish reactivity. Heating slow reactions may be effective, but the risk of decomposing the desired HVI compound or intermediate is a concern. Altering the solvent of a reaction is an important step in optimizing a reaction's efficiency as well the yield of the desired product. Creation of HVI reagents that have similar reactivity to that of PIDA, but different solubility profiles should allow for more control over optimization of reaction conditions. While there has been much effort in developing HVI reagents and conditions for transformations in water as a solvent, ${ }^{20}$ less attention has been paid to making these compounds more soluble in non-polar solvents. Creation of iodonium ylides with improved solubility profiles has markedly increased the utility of that class of HVI reagents. ${ }^{21-23}$

The synthesis of HVI compounds, many of which use PIDA as a starting material, often require isolation via precipitation and/or recrystallization. Isolation procedures for a novel HVI compound rely on its solubility in halogenated solvents or acetonitrile, and its insolubility in ether or hexane. The strict limitations of solubility of HVI compounds results in failed attempts to synthesize, isolate, and purify novel HVI compounds by modifying literature procedures. Herein, we present relevant solubility data for PIDA and the also commonly used phenyliodine bis(trifluoroacetate) (PIFA), as well as PIDA derivatives containing di-substituted butanoate, or decanoate in place of the acetate groups. Fundamental solubility data on PIDA and PIFA solubility should be useful to those who utilize these reagents. By providing solubility data for PIDA and PIFA as well as butanoate and decanoate derivatives, we hope to expand the library of these fascinating molecules and open up new reactions in underutilized solvents. ${ }^{19}$

\section{Results and Discussion}

The most common solvents for reactions containing hypervalent iodides are acetonitrile and dichloromethane. ${ }^{2,3,10}$ The prevalence of these solvents in hypervalent iodide reactions is due in part to the solubility of the commonly used phenyliodonium diacetate in these two solvents. However, what information exists in the literature about the solubility of hypervalent iodides is qualitative rather than quantitative, such as that PIDA (1, Table 1) is soluble in acetonitrile and dichloromethane, but without any numbers that would suggest the relative solubility in each solvent. ${ }^{24}$ Examination of the solubility of 1 at $20{ }^{\circ} \mathrm{C}$ reveals that 1 is more than four times as soluble in $\mathrm{CH}_{2} \mathrm{Cl}_{2}$ as in $\mathrm{CH}_{3} \mathrm{CN}$ (entries 1 and 2, Table 1). Perhaps surprisingly, 1 is approximately as soluble in tetrahydrofuran (entry 3 ), a solvent $\mathbf{1}$ is rarely used with, as it is in acetonitrile. In the less polar diethyl ether (entry 4), the solubility of 1 decreases by nearly eight times compared with tetrahydrofuran. Solubility of $\mathbf{1}$ in toluene is $12.9 \mathrm{mg} / \mathrm{mL}$, but $\mathbf{1}$ is unsurprisingly insoluble in hexanes (entries 5 and 6). Phenyliodine bis(trifluoroacetate) $\mathbf{2}$ is noticeably more soluble than $\mathbf{1}$ in every solvent examined (entries 
7-12) with the exception of $\mathrm{CH}_{2} \mathrm{Cl}_{2}$ in which $\mathbf{2}$ is somewhat less soluble. PIFA (2) is more than eight times as soluble as PIDA 1 in tetrahydrofuran, $\mathrm{CH}_{3} \mathrm{CN}$, diethyl ether and toluene. Much like acetic acid derived 1, trifluoroacetic acid derived $\mathbf{2}$ is noticeably more soluble in tetrahydrofuran than diethyl ether (entries 9 and 10) and has a solubility in toluene and diethyl ether that is similar (entries 10 and 11). While not completely insoluble in hexanes, $\mathbf{2}$ nonetheless is barely soluble in hexanes (entry 12).

Table1. Solubility of hypervalent iodides in a variety of solvents

\begin{tabular}{|c|c|c|c|c|c|}
\hline \multirow[b]{2}{*}{ entry } & 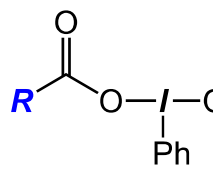 & $\mathrm{O}_{R}^{\mathrm{O}}$ & $\begin{array}{l}\boldsymbol{R}=\mathrm{CH}_{3}, \mathbf{1} \\
\boldsymbol{R}=\mathrm{CF}_{3}, \mathbf{2}\end{array}$ & \multicolumn{2}{|c|}{ Measured at $20^{\circ} \mathrm{C}$} \\
\hline & substrate & solvent & solubility $(\mathrm{mg} / \mathrm{mL})^{\text {a }}$ & solubility (mmol/mL) & $\%$ RSD \\
\hline 1 & 1 & $\mathrm{CH}_{3} \mathrm{CN}$ & 59.8 & 0.186 & 10.3 \\
\hline 2 & 1 & $\mathrm{CH}_{2} \mathrm{Cl}_{2}$ & $2.80 \times 10^{2}$ & 0.869 & 2.4 \\
\hline 3 & 1 & THF & 57.2 & 0.178 & 3.7 \\
\hline 4 & 1 & $\mathrm{Et}_{2} \mathrm{O}$ & 7.6 & $2.4 \times 10^{-2}$ & 3.2 \\
\hline 5 & 1 & toluene & 12.9 & $4.00 \times 10^{-1}$ & 8.1 \\
\hline 6 & 1 & hexanes & $<0.5^{b}$ & $N / A^{b}$ & N/A \\
\hline 7 & 2 & $\mathrm{CH}_{3} \mathrm{CN}$ & 539 & 1.25 & 2.9 \\
\hline 8 & 2 & $\mathrm{CH}_{2} \mathrm{Cl}_{2}$ & 235 & 0.546 & 2.0 \\
\hline 9 & 2 & THF & 648 & 1.51 & 8.2 \\
\hline 10 & 2 & $\mathrm{Et}_{2} \mathrm{O}$ & 142 & 0.330 & 2.3 \\
\hline 11 & 2 & toluene & 111 & 0.258 & 6.1 \\
\hline 12 & 2 & hexanes & 0.9 & $2 \times 10^{-3}$ & 9.1 \\
\hline 13 & 3 & $\mathrm{CH}_{3} \mathrm{CN}$ & 4.4 & $1.16 \times 10^{-3}$ & 17.5 \\
\hline 14 & 3 & $\mathrm{CH}_{2} \mathrm{Cl}_{2}$ & 18.7 & $4.94 \times 10^{-2}$ & 1.5 \\
\hline 15 & 3 & THF & 5.1 & $1.4 \times 10^{-2}$ & 21.1 \\
\hline 16 & 3 & $\mathrm{Et}_{2} \mathrm{O}$ & 24.8 & $6.56 \times 10^{-2}$ & 5.9 \\
\hline 17 & 3 & toluene & 5.4 & $1.3 \times 10^{-2}$ & 12.8 \\
\hline 18 & 3 & hexanes & $<0.5^{b}$ & $N / A^{b}$ & N/A \\
\hline 19 & 4 & $\mathrm{CH}_{3} \mathrm{CN}$ & 2.7 & $4.94 \times 10^{-3}$ & 3.8 \\
\hline 20 & 4 & $\mathrm{CH}_{2} \mathrm{Cl}_{2}$ & 39.7 & $7.26 \times 10^{-2}$ & 17.8 \\
\hline 21 & 4 & THF & 195 & 0.357 & 0.8 \\
\hline 22 & 4 & $\mathrm{Et}_{2} \mathrm{O}$ & 82.4 & 0.151 & 20.9 \\
\hline 23 & 4 & toluene & 23.3 & $4.26 \times 10^{-2}$ & 15.9 \\
\hline 24 & 4 & hexanes & 10.6 & $1.94 \times 10^{-2}$ & 13.4 \\
\hline
\end{tabular}

${ }^{\text {a }}$ Average of four experiments. ${ }^{b}$ Solubilities of less than $0.5 \mathrm{mg} / \mathrm{mL}$ reflect compounds that were essentially insoluble.

Hypothesizing that a longer aliphatic chain of the carboxyl group of the hypervalent iodide would increase solubility in less polar solvents, butyric acid derived $\mathbf{3}$ was synthesized and its solubility was measured. Compound $\mathbf{3}$ is known in the literature, ${ }^{25-31}$ but it is mostly employed in reactions where the carboxylic acid 
moiety of the HVI is transferred. The solubility of $\mathbf{3}$ has not been reported. lodane $\mathbf{3}$ has lower solubility than $\mathbf{1}$ in all solvents examined with the exception of diethyl ether, for which it has a higher solubility than 1 (entries 13 to 18). Even with the longer alkyl chain, $\mathbf{3}$ is still insoluble in hexanes, indicating that the additional $\mathrm{C}-\mathrm{H}$ bonds in $\mathbf{3}$ were not enough to overcome the inherent polarity of the iodane. However, the decanoic acid derived $\mathbf{4}$ has ten times the solubility of even $\mathbf{2}$ in hexanes (entry 24). ${ }^{32,33}$ and is the only compound investigated to show significant solubility in hexanes. Interestingly, $\mathbf{4}$ is approximately $5 \%$ as soluble in acetonitrile as $\mathbf{1}$ and less than $10 \%$ as soluble in $\mathrm{CH}_{2} \mathrm{Cl}_{2}$ as 1 . Both of these results fit with 4 having decreased polarity compared to 1 . lodane 4 is more soluble in both diethyl ether and tetrahydrofuran than $\mathbf{1}$.

It is important to note that qualitatively assessing the solubility of hypervalent iodine species (such as 14 ) is fraught with difficulty. For example, a solution of PIDA 1 in $\mathrm{CH}_{2} \mathrm{Cl}_{2}$ becomes cloudy and opaque (and therefore may appear to be saturated) at concentrations greater than $40 \mathrm{mg} / \mathrm{mL}$, but the solution does not become saturated until concentrations of $2.20 \times 10^{2} \mathrm{mg} / \mathrm{mL}$ (entry 1, Table 1). Such knowledge can allow experimentalists to minimize the amounts of solvent used in transformations with hypervalent iodides to decrease the environmental impact of these transformations.

\section{Conclusions}

The solubility of PIDA, PIFA, and PIDA derivatives was investigated in common organic solvents. It was found that the longer alkyl chain of the PIDA derivatives $\mathbf{3}$ and $\mathbf{4}$ were more soluble in nonpolar solvents like ether and hexane then simple PIDA. PIFA and the PIDA derivatives were synthesized via a ligand exchange reaction to alter the acetate moiety of PIDA. Based on this approach, novel HVI compounds can be used in solvents that otherwise would be unsuitable to traditional reactions with HVI reagents.

\section{Experimental Section}

General. All reactions were performed in oven-dried glassware. All solubility measurements were carried out in undried glassware without special precaution to exclude air. Unless otherwise noted, all solvents and reagents were obtained from commercial sources and used without further purification. In the solubility studies, diethyl ether (>99\%, inhibitor free; Beantown Chemical), tetrahydrofuran (>99.9\%, inhibitor free; Honeywell) and acetonitrile (99.8\%, anhydrous; Fisher Scientific) were sparged with nitrogen gas and passed through two columns of activated alumina on an LC Technology solvent purification system prior to use. NMR data of synthesized compounds matched what was previously reported. Infrared (IR) spectra were recorded on a Bruker ALPHA spectrometer with $\lambda_{\max }$ in $\mathrm{cm}^{-1}$. A Bruker Avance III $500 \mathrm{MHz}$ spectrometer was used to record the ${ }^{1} \mathrm{H}$ and ${ }^{13} \mathrm{C} \mathrm{NMR}$ spectra in $\mathrm{CDCl}_{3}$. The solvent resonance was used as the internal standard with $\mathrm{CDCl}_{3} \delta 7.26 \mathrm{ppm}$ for ${ }^{1} \mathrm{H}$ NMR and $\delta 77.16 \mathrm{ppm}$ for ${ }^{13} \mathrm{C}$ NMR. ${ }^{1} \mathrm{H}$ NMR data is reported as chemical shift ( $\delta, \mathrm{ppm}$ ), multiplicity (s, singlet; $d$, doublet; $t$, triplet; $q$, quartet; $m$, multiplet), integration, and coupling constant $(\mathrm{Hz})$, while ${ }^{13} \mathrm{C}$ is reported as chemical shift $(\delta, \mathrm{ppm})$.

General procedure A. Procedure is in accordance with that reported by Wang et al. ${ }^{34} \mathrm{PhI}(\mathrm{OAc})_{2}(1.0$ equiv.) and carboxylic acid (2.2 equiv.) was dissolved in chloroform $\left(\mathrm{CHCl}_{3}\right)$ at $55^{\circ} \mathrm{C}$ and allowed to stir for $1 \mathrm{~h}$ under $\mathrm{N}_{2}$, unless otherwise stated. The reaction was quenched with saturated bicarbonate and extracted with hexane or chloroform. The combined organic layers were dried over anhydrous $\mathrm{Na}_{2} \mathrm{SO}_{4}$ and then concentrated in vacuo. If crude mixture did not solidify to white solid, an additional aqueous extraction with saturated bicarbonate was performed. 
General procedure B. Procedure is in accordance with that reported by Wengryniuk et al. ${ }^{11} \mathrm{Phl}(\mathrm{OAc})_{2}(1.0$ equiv.) was dissolved in carboxylic acid (6.75 equiv.) and allowed to stir at $55^{\circ} \mathrm{C}$ under $\mathrm{N}_{2}$ for $1 \mathrm{~h}$. The crude reaction mixture was then cooled in an ice bath to afford a white crystalline solid.

Sample solubility measurement of phenyliodonium diacetate (1) in diethyl ether. Following the procedure and set up from Malwade et al., ${ }^{35} 110 \mathrm{mg}$ of 1 was weighed into an $8 \mathrm{~mL}$ vial equipped with a Teflon coated stir bar. Diethyl ether $(5.0 \mathrm{~mL})$ was transferred to the vials via a syringe to form a saturated solution of $1(21 \mathrm{mg} / \mathrm{mL}) \mathrm{in}$ diethyl ether. The vial was sealed with a PTFE-lined cap and further sealed with electrical tape. This saturated solution was allowed to stir for $24 \mathrm{~h}$ in an isothermal bath at $20 \pm 0.1$ ㅇ C controlled by a PolyScience LM Series $1 / 3$ HP benchtop chiller. The vial was removed from the isothermal bath and the solution was quickly filtered through a PTFE $0.22 \mu \mathrm{m}$ porosity syringe filter. Two aliquots $(2.00 \mathrm{~mL})$ of the filtered solution were then measured into tared vials. The vials were concentrated in vacuo and dried on a high-vacuum pump until the masses did not change by more than $2 \%$ between weighing to afford $15.6 \mathrm{mg}$ of 1 in the first vial and $14.8 \mathrm{mg}$ of 1 in the second vial. Dividing by volume gives solubility of 7.80 and $7.40 \mathrm{mg} / \mathrm{mL}$ respectively. The vapor pressure of 1 was high enough that a known about amount 1 did not decrease in mass even after $48 \mathrm{~h}$ on high vacuum, which makes it unlikely that loss of 1 during drying contributes meaningfully to the error. All solubility measurements were carried out in a similar manner.

Phenyl- $\lambda^{3}$-iodanediyl bis(decanoate) (4). Following General procedure A, a mixture of PIDA (5.0 mmol, $1.61 \mathrm{~g}$ ) and decanoic acid $(11.0 \mathrm{mmol}, 1.89 \mathrm{~g})$ in $50.0 \mathrm{~mL} \mathrm{CHCl}_{3}$ was allowed to stir at $55^{\circ} \mathrm{C}$ under $\mathrm{N}_{2}$ for $1 \mathrm{~h}$. The reaction was then cooled to room temperature and concentrated in vacuo to yield a viscous oil. The crude oil is quenched with saturated bicarbonate and extracted with hexane $(3 \times 20 \mathrm{~mL})$. The combined organic layers were dried over anhydrous $\mathrm{Na}_{2} \mathrm{SO}_{4}$ and concentrated in vacuo to yield a white solid. An additional aqueous extraction with saturated bicarbonate was performed if oil did not solidify to a white solid. The white solid is washed with deionized water and filtered off to afford compound (4) with a yield of $80 \%$. ${ }^{1} \mathrm{H} \mathrm{NMR}\left(500 \mathrm{MHz}, \mathrm{CDCl}_{3}\right): \delta 8.08$ (dd, J 6.31, 5.04 Hz, 2 H), 7.58 (t, J $9.77 \mathrm{~Hz}, 1 \mathrm{H}$ ), 7.49 (t, J $10.09 \mathrm{~Hz}, 2 \mathrm{H}), 2.25$ (t, J $7.57 \mathrm{~Hz}, 4 \mathrm{H}), 1.54$ (t, J 7.09 $\mathrm{Hz}, 4 \mathrm{H}), 1.21-1.31(\mathrm{~m}, 36 \mathrm{H}), 0.88(\mathrm{t}, J 7.09 \mathrm{~Hz}, 9 \mathrm{H}) .{ }^{13} \mathrm{C} \mathrm{NMR}\left(126 \mathrm{MHz}, \mathrm{CDCl}_{3}\right): \delta 178.96,134.85,131.55$, $130.81,121.84,34.04,31.85,29.40,29.24,29.20,25.65,22.64,14.09$.

Phenyl- $\boldsymbol{\lambda}^{3}$-iodanediyl dibutanoate (3). Following General procedure A, a solution of PIDA (5.00 mmol, $1.61 \mathrm{~g}$ ) and butyric acid $(50.00 \mathrm{mmol}, 4.41 \mathrm{~g})$ was allowed to stir at $55^{\circ} \mathrm{C}$ under $\mathrm{N}_{2}$ for $48 \mathrm{~h}$. The reaction was cooled to room temperature and concentrated in vacuo to yield a viscous oil. Saturated bicarbonate was added to this oil and the aqueous layer was extracted with $\mathrm{CHCl}_{3}(3 \times 20 \mathrm{~mL})$. The combined organic layers were dried over anhydrous $\mathrm{Na}_{2} \mathrm{SO}_{4}$ and concentrated in vacuo to yield a white solid. Compound (3) was obtained as a white solid with a yield of 95\%. ${ }^{1} \mathrm{H} N M R\left(500 \mathrm{MHz}, \mathrm{CDCl}_{3}\right): \delta 8.09(\mathrm{dd}, J 7.25,6.31 \mathrm{~Hz}, 2 \mathrm{H}), 7.59(\mathrm{t}, J 9.46 \mathrm{~Hz}, 1 \mathrm{H}), 7.50(\mathrm{t}, J$ $11.35 \mathrm{~Hz}, 2 \mathrm{H}), 2.25(\mathrm{t}, J 10.40 \mathrm{~Hz}, 4 \mathrm{H}), 1.54-1.62(\mathrm{~m}, 7 \mathrm{H}), 0.89(\mathrm{t}, J 8.83 \mathrm{~Hz}, 6 \mathrm{H})$.

${ }^{13} \mathrm{C} \mathrm{NMR}\left(126 \mathrm{MHz}_{2} \mathrm{CDCl}_{3}\right): \delta 178.76,134.84,131.56,130.83,121.79,35.93,19.11,13.71$.

Phenyl- $\lambda^{3}$-iodanediyl bis(2,2,2-trifluoroacetate) (2). Following General procedure B, a solution of PIDA (15.5 $\mathrm{mmol}, 5.00 \mathrm{~g})$ and trifluoroacetic acid $\left(104.54 \mathrm{mmol}, 8.0 \mathrm{~mL}\right.$ ) was allowed to stir at $55^{\circ} \mathrm{C}$ under $\mathrm{N}_{2}$ for $1 \mathrm{~h}$. An additional $3.0 \mathrm{~mL}$ of trifluoroacetic acid was added to obtain a homogenous solution. The reaction was allowed to cool to room temperature and placed in an ice bath to afford a crystalline white solid. The white solid was filtered and washed with pentane to give compound (2) with a yield of $82 \%$. Spectral data was consistent with what is reported in the literature. ${ }^{1} \mathrm{H}$ NMR $\left(500 \mathrm{MHz}, \mathrm{CDCl}_{3}\right): \delta 8.21$ (dd, J 6.94, $\left.5.36 \mathrm{~Hz}, 2 \mathrm{H}\right), 7.75$ (ttt, J 9.14 , 9.14, 2.84, 2.84, 1.58, 1.58 Hz, $1 \mathrm{H}), 7.63(\mathrm{t}, J 11.03 \mathrm{~Hz}, 2 \mathrm{H})$.

$\left.{ }^{19} \mathrm{~F} \mathrm{NMR}\left(471 \mathrm{MHz}^{\mathrm{CDCl}}\right)_{3}\right): \delta-73.44$. 


\section{Acknowledgements}

The research conducted was supported by Adelphi University Faculty Development Grants, the Frederick Bettelheim Research Award, McDonell Fellowships, the Landesberg Fellowship, and the ACS PRF\# 59555-UNI1.

\section{Supplementary Material}

Supplementary data associated with this article can be found in the online version.

\section{References}

1. Stang, P. J.; Zhdankin, V. V. Chem. Rev. 1996, 96, 1123-1178.

https://doi.org/10.1021/CR940424+.

2. Zhdankin, V. V. Hypervalent lodine Chemistry: Preparation, Structure, and Synthetic Applications of Polyvalent lodine Compounds; John Wiley \& Sons Ltd: Chichester, UK, 2014.

https://doi.org/10.1002/9781118341155

3. Yoshimura, A.; Zhdankin, V. V. Chem. Rev. 2016, 116, 3328-3435.

https://doi.org/10.1021/acs.chemrev.5b00547

4. Grelier, G.; Darses, B.; Dauban, P. Beilstein J. Org. Chem. 2018, 14, 1508-1528.

https://doi.org/10.3762/bjoc.14.128

5. Walters, J. C.; Tierno, A. F.; Dubin, A. H.; Wengryniuk, S. E. Eur. J. Org. Chem. 2018, 2018, 1460-1464. https://doi.org/10.1002/ejoc.201800118

6. Huang, H.; Zhang, G.; Chen, Y. Angew. Chem. Int. Ed. 2015, 54, 7872-7876.

https://doi.org/https://doi.org/10.1002/anie.201502369

7. Huang, H.; Jia, K.; Chen, Y. Angew. Chem. Int. Ed. 2015, 54, 1881-1884.

\section{https://doi.org/10.1002/anie.201410176}

8. Dave, L.; Mowdawalla, C.; Ahmed, F.; Hyatt, I. F. D.; Li, T.; Kim, G.; Pham, K. Beilstein J. Org. Chem. 2018, 14, 1039-1045.

https://doi.org/10.3762/bjoc.14.91

9. Khatri, H. R.; Zhu, J. Chem. Eur. J. 2012, 18, 12232-12236.

https://doi.org/10.1002/chem.201202049

10. Hyatt, I. F. D.; Dave, L.; David, N.; Kaur, K.; Medard, M.; Mowdawalla, C. Org. Biomol. Chem. 2019, 17, 7288-7848.

\section{https://doi.org/10.1039/c9ob01267b}

11. Sousa E Silva, F. C.; Van, N. T.; Wengryniuk, S. E. J. Am. Chem. Soc. 2020, 142, 64-69. https://doi.org/10.1021/jacs.9b11282

12. Zhao, J.; Li, S. J. Org. Chem. 2017, 82, 2984-2991. https://doi.org/10.1021/acs.joc.6b03050.

13. Chen, W. W.; Cuenca, A. B.; Shafir, A. Angew. Chem. Int. Ed. 2020, 59, 16294-16309. https://doi.org/10.1002/anie.201908418

14. Varvoglis, A. The Organic Chemistry of Polycoordinated lodine; VCH, 1992.

15. Zhdankin, V. V. Reviews on Heteroatom Chemistry. M Y U Scientific Publishing Division December 1997, pp 133-151.

16. Morales-Rojas, H.; Moss, R. A. Chem. Rev. 2002, 102, 2497-2521. 
17. Moriarty, R. M. J. Org. Chem. 2005, 70, 2893-2903.

https://doi.org/10.1021/jo050117b

18. Zhdankin, V. Curr. Org. Synth. 2005, 2, 121-145.

https://doi.org/10.2174/1570179052996982

19. Zhdankin, V. V. Arkivoc 2020, (iv), 1-11.

https://doi.org/10.24820/ark.5550190.p011.145

20. Han, Y. C.; Zhang, C. Tetrahedron Lett. 2018, 59, 3052-3064.

https://doi.org/10.1016/j.tetlet.2018.06.059

21. Macikenas, D.; Skrzypczak-Jankun, E.; Protasiewicz, J. D. J. Am. Chem. Soc. 1999, 121, 7164-7165.

https://doi.org/10.1021/ja991094j

22. Zhu, C.; Yoshimura, A.; Ji, L.; Wei, Y.; Nemykin, V. N.; Zhdankin, V. V. Org. Lett. 2012, 14, 3170-3173.

https://doi.org/10.1021/ol301268j

23. Zhu, C.; Yoshimura, A.; Solntsev, P.; Ji, L.; Wei, Y.; Nemykin, V. N.; Zhdankin, V. V. Chem. Commun. 2012, 48, 10108-10110.

https://doi.org/10.1039/c2cc35708a

24. Moriarty, R. M.; Chany II, C. J.; Kosmeder II, J. W.; Du Bois, J. (DIACETOXYIODO)BENZENE. Encyclopedia of Reagents for Organic Synthesis; 2006; pp 1-9.

https://doi.org/10.1002/047084289X.rd005m.pub2.

25. Merkushev, E. B.; Novikov, A. N.; Makarchenko, S. S.; Moskal'chuk, A. S.; GLushkova, V. V.; Kogai, T. I.; Polyakova, L. G. Zh. Org. Khim. 1975, 11, 1259-1263.

26. Zalatan, D. N.; Du Bois, J. J. Am. Chem. Soc. 2009, 131, 7558-7559.

https://doi.org/10.1021/ja902893u

27. Wang, Y.; Zhang, L.; Yang, Y.; Zhang, P.; Du, Z.; Wang, C. J. Am. Chem. Soc. 2013, 135, 18048-18051. https://doi.org/10.1021/ja410195j

28. Guo, S.; Santhosh Kumar, P.; Yuan, Y.; Yang, M. Eur. J. Org. Chem. 2016, 2016, 4260-4264.

https://doi.org/10.1002/ejoc.201600632

29. Maity, A.; Hyun, S. M.; Powers, D. C. Nat. Chem. 2018, 10, 200-204.

https://doi.org/10.1038/nchem.2873

30. Wang, L.; Zhao, J.; Sun, Y.; Zhang, H. Y.; Zhang, Y. Eur. J. Org. Chem. 2019, 2019, 6935-6944. https://doi.org/10.1002/ejoc.201901266

31. Zhang, L.; Wang, Y.; Yang, Y.; Zhang, P.; Wang, C. Org. Chem. Front. 2020, 7, 3234-3241. https://doi.org/10.1039/d0q000953a

32. Dick, A. R.; Kampf, J. W.; Sanford, M. S. J. Am. Chem. Soc. 2005, 127, 12790-12791. https://doi.org/10.1021/ja0541940

33. Racowski, J. M.; Dick, A. R.; Sanford, M. S. J. Am. Chem. Soc. 2009, 131, 10974-10983. https://doi.org/10.1021/ja9014474

34. Jeyakannu, P.; Chandru Senadi, G.; Chiang, C.; Kumar Dhandabani, G.; Chang, Y.; Wang, J. Adv. Synth. Catal. 2020, 362, 2911-2920.

https://doi.org/10.1002/adsc.202000402

35. Malwade, C. R.; Christensen, L. P. Educ. Chem. Eng. 2016, 16, 29-38.

https://doi.org/10.1016/j.ece.2016.06.003

This paper is an open access article distributed under the terms of the Creative Commons Attribution (CC BY) license (http://creativecommons.org/licenses/by/4.0/) 